\section{Editorial}

\section{From Editor-in-Chief}

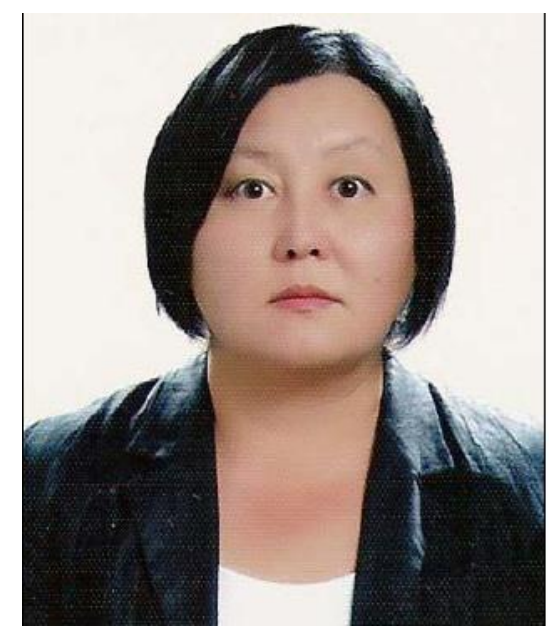

Dear readers

Just a brief note, about updates regarding our journal. For past year, our website access reached 465 cities around the world. We continue putting all our efforts to make our journal accessible elsewhere and apply transparent editorial policies. We are included already in several indexing databases that certainly ease access from many countries, all our review and research manuscripts received the high readability statistics as well. We start this year with $4^{\text {th }}$ issue of the journal since launch of $1^{\text {st }}$ issue or $1^{\text {st }}$ issue of volume 2 and we continue unbiased peer-review of submitted manuscripts. As in previous issues, for this year you can find the editorial written by our editors as well as the invited reviews on the most hot topics in medicine and all relevant disciplines, research articles and brief reports. We set goals and we move forward. We look forward for submission of articles worldwide.

Gulmira Kudaiberdieva

Editor-in-Chief

Heart Vessels and Transplantation

\title{
Heart Vessels and Transplantation
}

Copyright 2018

Received: 09.03.2018 Accepted: 09.03.2018

Doi: 